\title{
Improving the antioxidant activity of buckwheat (Fagopyrum tataricm Gaertn) sprout with trace element water
}

\author{
Cheng-Kuang Hsu ${ }^{\text {a }}$, Been-Huang Chiang ${ }^{b}$, Yih-Shyuan Chen ${ }^{c}$, \\ Joan-Hwa Yang ${ }^{c}$, Chia-Ling Liu ${ }^{\mathrm{c}, *}$ \\ ${ }^{a}$ Department of Applied Life Science, Asia University, No. 500, Lioufeng Road, Wufeng Shiang, Taichung 413, Taiwan, ROC \\ ${ }^{\mathrm{b}}$ Institute of Food Science and Technology, National Taiwan University, No. 1, Section 4, Roosevelt Road, Taipei 106, Taiwan, ROC \\ ${ }^{\mathrm{c}}$ Department of Food Science, Nutrition and Nutraceutical Biotechnology, Shih Chien University, 70 Ta-chih Street, Taipei 104, Taiwan, ROC
}

Received 13 June 2007; received in revised form 3 October 2007; accepted 14 November 2007

\begin{abstract}
Trace element water (TEW) (100, 200, 300, 400 and 500 ppm) was used to grow buckwheat (Fagopyrum tataricm Gaertn) to evaluate whether the beneficial effects of trace elements on the antioxidant activity could be accomplished with the supplement of TEW. At $300 \mathrm{ppm}$, TEW significantly increased the $\mathrm{Cu}, \mathrm{Zn}$ and Fe contents in buckwheat sprout, but not the Se and Mn contents. The levels of rutin, quercitrin and quercetin did not differ between buckwheat sprouts grown in TEW and de-ionized water (DIW). The ethanolic extract from buckwheat sprout grown in 300 ppm TEW showed higher DPPH radical scavenging activity, ferrous ion chelating activity, superoxide anion scavenging activity and inhibitory activity toward lipid peroxidation than that grown in DIW. The extract of the TEW group also enhanced intracellular superoxide dismutase activity and resulted in lower level of reactive oxygen species in human Hep G2 cells.
\end{abstract}

(C) 2007 Elsevier Ltd. All rights reserved.

Keywords: Buckwheat; Fagopyrum tataricm Gaertn; Trace element water; Antioxidant; Rutin

\section{Introduction}

Buckwheat is grown in many countries in Asia, Europe, South Africa, Canada, USA, Brazil and in certain other places around the world. The most popular derivative food is buckwheat noodles, very popular in Japan, China and Italy, made from buckwheat flour-water dough. The presence of rutin in buckwheat is one of the main reasons for the production of different kinds of buckwheat foods (Kreft, Fabjan, \& Yasumoto, 2006). Among fruits, vegetables and grain crops, grapes and buckwheat are the most important rutin containing foods. No rutin was found in cereals and pseudocereals except buckwheat, which can be used as a good source of dietary rutin (Kreft, Knapp, \&

\footnotetext{
* Corresponding author. Tel.: +886 2 25381111x6229; fax: +886 2 25334789.

E-mail address: cll@mail.usc.edu.tw (C.-L. Liu).
}

Kreft, 1999; Park et al., 2000). Rutin is a secondary plant metabolite that antagonizes the increase of capillary fragility associated with haemorrhagic disease, reduces high blood pressure (Abeywardena \& Head, 2001), decreases the permeability of the blood vessels and has an antioedema effect, reduces the risk of arteriosclerosis (Wojcicki, Barcew-Wiszniewska, Samochowiec, \& Rozewicka, 1995) and has antioxidant activity (Park et al., 2000).

Trace element status is very important to maintain biological functions in all living organisms. Trace elements are involved in the antioxidant responses, inflammation, wound healing and immune responses (Prohaska \& Luckasewycz, 1981; Roussel, Anderson, \& Favier, 2000). For the antioxidant system, several trace elements are involved in the main cellular defenses against reactive oxygen species (ROS), as co-factors of superoxide dismutase (SOD) or glutathione peroxidase (GPx) (Geret \& Bebianno, 2004; Steinman, 1982; Wichtel, 1998). These enzymes protect cell 
membranes from damage caused by the peroxidation of lipids. For example, manganese $(\mathrm{Mn})$ plays a major antioxidant role, both as Mn-SOD co-factor and as a direct ROS scavenger. Zinc ( $\mathrm{Zn})$ can stimulate the activity of SOD. Selenium (Se) is an essential trace element for animals and humans because of its role in GPx (Tinggi, 2003). In this study, the effect of trace element water on the antioxidant activity of buckwheat sprout was determined. Measurement of antioxidant activities included reducing power, DPPH radical scavenging activity, ferrous ion chelating activity and inhibitory activity toward lipid peroxidation, as well as intracellular antioxidant enzyme activities, reactive oxygen species and superoxide anion in human Hep G2 cells.

\section{Materials and methods}

\subsection{Materials}

Buckwheat (Fagopyrum tataricm Gaertn) seed was obtained from Taichung District Agricultural Research and Extension Station, Council of Agriculture Executive Yuan, Taichung, Taiwan. Trace element water (TEW) was obtained from Shimanishi Kaken Co., Ltd. (Tokyo, Japan). Human hepatoma cell line (HepG2 cells) was obtained from Bioinformatics Lab., BCRC, Food Industry Research and Development Institute (Shinzu, Taiwan).

Rutin, quercetin, quercitrin, ascorbic acid, butylated hydroxytoluene (BHT), 2',7'-dichlorofluorescein diacetate (DCFH-DA), dihydroethidium (DHE), dimethyl sulfoxide (DMSO), 1,1-diphenyl-2-picrylhydrazyl (DPPH), ferrozine, linoleic acid, 3-(4,5-dimethylthiazol-2-yl)-2,5-diphenyl-teyrazolium bromide (MTT), $\beta$-nicotinamide adenine dinucleotide ( $\beta$-NADH), and $\alpha$-tocopherol were purchased from Sigma Chemicals Co. (St. Louis, MO, USA). Isovitexin, orientin and vitexin were purchased from Fluka ChemikaBiochemika Co. (Ronkonkoma, NY, USA). Potassium dihydrogen phosphate $\left(\mathrm{KH}_{2} \mathrm{PO}_{4}\right)$ and pyrogallol were obtained from Merck Co. (Darmstadt, Germany). Ferric chloride, calcium carbonate, and Tween 20 were purchased form Kanto Chemical Co. (Tokyo, Japan). Ammonium thiocyanate and sodium phosphate were purchased form Shimakyu Co. (Osaka, Japan). Phenazine methosulfate (PMS) and nitro blue terazolium chloride monohydrate (NBT) were purchased form Acros Organics (Phillipsburg, NJ, USA). Dulbecco's Modified Eagle Medium (DMEM) was purchased from GIBCOTM Co. (NY, USA). Fetal bovine serum (FBS) was purchased from BenchMark ${ }^{\text {TM }}$ Gemin Bio-Products (Woodland, CA). Isoorientin was obtained from Chromadex Co. (Daimler St Santa Ana, CA).

\subsection{Plant materials and growth conditions}

Buckwheat seed was immersed in water for $6 \mathrm{~h}$ and then put into a bag for germination for $12-15 \mathrm{~h}$. The seed was sown in a plate with sandy soil $(35 \times 25 \times 3 \mathrm{~cm})$. The plate was put in a plant incubator (Hotech, 624HD LE-539, Tai- pei, Taiwan) at $25 \pm 2{ }^{\circ} \mathrm{C}$ with $12 \mathrm{~h}$ sunlight and sprayed with water at intervals of $4 \mathrm{~h}$ everyday. The water used to grow buckwheat was TEW with the concentrations of $100,200,300,400$ and $500 \mathrm{ppm}$, while de-ionized water (DIW) was used as the control. The $\mathrm{pH}$ values of TEW at the concentration of $100,200,300,400$ and $500 \mathrm{ppm}$ were 3.54, 3.28, 3.12, 3.01 and 2.88, respectively. Saturated $\mathrm{CaCO}_{3}$ solution was used to adjust the $\mathrm{pH}$ of TEW to 6.2 6.5. After 6-7 days, buckwheat sprouts (about 5-7 cm) were harvested and freeze-dried. Dried buckwheat sprouts were milled and stored at $4{ }^{\circ} \mathrm{C}$ until use.

\subsection{Composition determination}

The analysis of the protein, lipid, moisture, ash, and fiber contents of buckwheat sprouts was performed according to standard AOAC methods (AOAC, 1997).

\subsection{Determination of trace elements}

Freeze-dried buckwheat sprout powder $(3 \mathrm{~g})$ or TEW was mixed with $10 \mathrm{ml}$ of $70 \%$ nitric acid, and digested in a closed digestion oven. After being liquefied, the sample volume was adjusted to $50 \mathrm{ml}$, and analyzed by an inductively coupled plasma mass spectrometry (ICP-MS, Agilent Technologies 7500C, Tokyo, Japan). The amount of sample components were calculated by the obtained values deducted from the blank values in accordance with their standard curves.

\subsection{Preparation of the ethanolic extract from buckwheat sprout}

Freeze-dried buckwheat sprout powder $(10 \mathrm{~g})$ was extracted twice with $100 \mathrm{ml}$ ethanol at $80^{\circ} \mathrm{C}$ for $3 \mathrm{~h}$ using a rotary vacuum evaporator (EYELA N-N series, Tokyo Rikakikai Co., Ltd., Tokyo, Japan). The ethanolic solution was filtrated with Whatman No. 1 paper, and then ethanol was removed in an evaporator at temperature lower than $40{ }^{\circ} \mathrm{C}$. The residue was freeze-dried (EYELA FDU-540, Tokyo Rikakikai Co., Ltd., Tokyo, Japan) and stored at $-20{ }^{\circ} \mathrm{C}$ until use.

\subsection{Determination of flavonoid compounds with HPLC analysis}

Buckwheat sprout powder or the ethanolic extract was dissolved in methanol and filtered through a nylon filter $(0.45 \mu \mathrm{m})$. The contents of isoorientin, vitexin, isovitexin and rutin in the mixtures were determined using high performance liquid chromatography (HPLC) (Hewlett Packard series 1100, Agilent Technologies, Inc., Santa Clara, CA, USA) with an internal standard, pyrogallol. The conditions for HPLC were: Zorbax 80A Extend C18 column $(5 \mu \mathrm{m}, 4.6 \times 250 \mathrm{~mm}$, Agilent technologies, Inc., Santa Clara, CA, USA); $5 \mu$ injection; $1 \mathrm{ml} / \mathrm{min}$ flow rate; ultraviolet detection at $254 \mathrm{~nm}$. The mobile phases were water 
(Mill-Q, 18.2 M $\Omega$ ) (mobile phase A) and methanol:acetic acid $(95: 5, \mathrm{v} / \mathrm{v})$ (mobile phase B). The gradient conditions were mobile phase B $0 \%, 20 \%, 40 \%, 50 \%, 70 \%$ and $100 \%$ at $0,10,20,30,40$ and $508 \mathrm{~min}$, respectively.

\subsection{Determination of DPPH radical scavenging activity}

DPPH radical-scavenging activity was measured according to the method of Shimada, Fujikawa, Yahara, and Nakamura (1992) with slight modification. The ethanolic extract $(1 \mathrm{ml})$ was mixed with $1 \mathrm{ml} 1 \mathrm{mM}$ DPPH (in methanol), then the mixture was shaken vigorously and left in the dark at room temperature for $30 \mathrm{~min}$. The absorbance of the resultant solution was measured by Helios Alpha UV-vis Spectrophotometer (Thermo Fisher Scientific, Inc., MA, USA) at $517 \mathrm{~nm}$. The DPPH radical scavenging activity was calculated as follows: scavenging activity $(\%)=\left[\left(A_{0}-\left(A-A_{\mathrm{b}}\right)\right) / A_{0}\right] \times 100 \%$, where $A_{0}$ was value of DPPH without sample; $A$ was value of sample and DPPH; $A_{\mathrm{b}}$ was value of sample without DPPH. Ascorbic acid, $\alpha$-tocopherol and BHT were used as positive controls.

\subsection{Determination of ferrous ion chelating activity}

Ferrous ion chelating activity of the sample solution was determined by the method of Dinis, Maderia, and Almeda (1994). The sample solution $(2 \mathrm{ml})$ was mixed with $0.6 \mathrm{ml}$ de-ionized water and $0.1 \mathrm{ml} 1 \mathrm{mM} \mathrm{FeCl}_{2}$, and then set at room temperature for $30 \mathrm{~s}$. The reaction was initiated by the addition of $0.2 \mathrm{ml} 2.5 \mathrm{mM}$ ferrozine for $10 \mathrm{~min}$, the absorbance of the mixture was measured using a Helios Alpha UV-vis Spectrophotometer (Thermo Fisher Scientific, Inc., MA, USA) at $562 \mathrm{~nm}$. Chelating activity $(\%)=$ $\left[1-\left(\right.\right.$ sample $A_{562 \mathrm{~nm}} /$ blank $\left.\left.A_{562 \mathrm{~nm}}\right)\right] \pm 100 \%$.

\subsection{Determination of superoxide anion scavenging activity}

Superoxide anion scavenging activity of the ethanolic extract from buckwheat sprout was based on the method described by Roback and Gryglewski (1988) with slight modification. One milli liter of nitroblue tetrazolium solution $(150 \mu \mathrm{M}$ in $100 \mathrm{mM}$ phosphate buffer, $\mathrm{pH} 7.4), 1 \mathrm{ml}$ $\mathrm{NADH}$ solution $(468 \mu \mathrm{M}$ in $100 \mathrm{mM}$ phosphate buffer, $\mathrm{pH} 7.4$ ) and $0.1 \mathrm{ml}$ of the ethanolic extract from buckwheat sprout were mixed. The reaction was started by adding $100 \mu \mathrm{l}$ of phenazine methosulphate solution $(60 \mu \mathrm{M}$ in $100 \mathrm{mM}$ phosphate buffer, $\mathrm{pH}$ 7.4) to the mixture. The reaction mixture was incubated at $25^{\circ} \mathrm{C}$ for $58 \mathrm{~min}$, and the absorbance at $560 \mathrm{~nm}$ was measured against blank samples. Decreased absorbance of the reaction mixture indicated increased superoxide anion scavenging activity. The percentage inhibition of superoxide anion generation was calculated using the following formula: \% scavenging activity $=\left[\left(A_{0}-A_{1}\right) / A_{0}\right] \times 100$; where $A_{0}$ was the absorbance of the control, and $A_{1}$ was the absorbance of the buckwheat sprout extract.

\subsection{Determination of the inhibitory activity toward lipid peroxidation}

The antioxidant activity was determined according to the method described by Misuda, Yasumoto, and Iwami (1966) with some modification. A $2.5 \mathrm{ml}$ aliquot of $0.02 \mathrm{M}$ linoleic acid emulsion $(0.2804 \mathrm{~g}$ linoleic acid and $0.2804 \mathrm{~g}$ Tween 20 in $50 \mathrm{ml}$ phosphate buffer, $\mathrm{pH} 7.0$ ) was mixed with $0.5 \mathrm{ml}$ sample solution and $2 \mathrm{ml}$ of $0.2 \mathrm{M}$ phosphate buffer $(\mathrm{pH}$ 7.0). After incubation at $50^{\circ} \mathrm{C}$ in the dark for $72 \mathrm{~h}$, a $0.1 \mathrm{ml}$ aliquot of the reaction solution was mixed with $4.7 \mathrm{ml}$ of ethanol $(75 \%), 0.1 \mathrm{ml}$ of ammonium thiocyanate $(30 \%)$ and $0.1 \mathrm{ml}$ of ferrous chloride $(20 \mathrm{mM})$. After the mixture was stirred for $3 \mathrm{~min}$, the peroxide value was determined by reading the absorbance at $500 \mathrm{~nm}$, and the inhibition percent of linoleic acid peroxidation was calculated as $(\%)$ inhibition $=[1-($ absorbance of sample at $500 \mathrm{~nm}) /$ (absorbance of control at $500 \mathrm{~nm}$ ) $] \times 100$. Ascorbic acid, $\alpha$-tocopherol and BHT $(0.1 \mathrm{mg} / \mathrm{ml})$ were used as positive control.

\subsection{Cell culture}

Human hepatoma HepG2 cells were purchased from Food Industry Research and Development Institute, Hsinchu, Taiwan. The cells were grown in a humidified incubator ( $90 \%$ humidity) with $5 \% \mathrm{CO}_{2}$ at $37{ }^{\circ} \mathrm{C}$. They were grown in Dulbecco's modified Eagle medium (DMEM) supplemented with $10 \%$ Biowhitaker fetal bovine serum (FBS). The culture medium was changed every other day and the cells were usually split 1:4 when they reached $80-90 \%$ confluence.

\subsection{Determination of cell viability}

The cells were plated in 96-well plates at an initial cell count of $1 \times 10^{4}$ per well and incubated at $37^{\circ} \mathrm{C}, 5 \% \mathrm{CO}_{2}$. After treating with different concentrations $(0.05-1 \mathrm{mg} / \mathrm{ml})$ of $100 \mu \mathrm{l}$ ethanolic extract from buckwheat sprout for 24 $72 \mathrm{~h}$, the cells were incubated with $2 \mathrm{mg} / \mathrm{ml} \mathrm{3-}(4$, 5-dimethylthiazol-2-yl)-2,5-diphenyl-tetrazolium bromide (MTT) $(100 \mu \mathrm{l})$ for $2.5 \mathrm{~h}$. Then the intracellular formazan product was dissolved in dimethyl sulfoxide (DMSO) $(100 \mu \mathrm{l})$ and quantified with an ELISA reader at $570 \mathrm{~nm}$.

\subsection{Determination of antioxidant enzymes activity}

The cells were plated in $60 \mathrm{~mm}$ diameter plates at a concentration of $4 \times 10^{6}$ per plate and incubated at $37^{\circ} \mathrm{C}, 5 \%$ $\mathrm{CO}_{2}$. The cells were pretreated with $5 \mathrm{ml}$ of $0.5 \mathrm{mg} / \mathrm{ml}$ ethanolic extract from buckwheat sprout for $6 \mathrm{~h}$. Then the plate was washed with phosphate buffered saline (PBS) twice. The cells were collected and broken by an ultrasonic processor, and then the supernatant was collected by centrifugation at $10,000 \mathrm{rpm}, 4{ }^{\circ} \mathrm{C}$ for $30 \mathrm{~min}$. Superoxide dismutase (SOD) activity was determined by the commercial kit, RANSOD SD-125 assay kit (Randox Laboratories 
Ltd., Ardmore, UK), while GPx activity was determined by RANSEL RS-504 assay kit (Randox Laboratories Ltd., Ardmore, UK).

\subsection{Determination of intracellular reactive oxygen species (ROS) and superoxide anion}

The intracellular ROS production was measured using a nonfluorescent compound $2^{\prime}, 7^{\prime}$-dichlorofluorescein diacetate (DCFH-DA) (LeBel, Ishiropoulos, \& Bondy, 1992). When this compound enters viable cells, it can be deacetylated to form $2^{\prime}, 7^{\prime}$-dichlorofluorescin (DCFH) which can react quantitatively with $\mathrm{ROC}$ within the cell to produce $2^{\prime}, 7^{\prime}$-dichlorofluorescein (DCF), which is fluorescent. In flow cytometry, DCF can produce green fluorescent $(535 \mathrm{~nm})$ and provide an index of intracellular oxidation (Wang \& Joseph, 1999). Superoxide anion can oxidize a membrane permeable substrate, dihydroethidium (DHE) to form a fluorescent compound, ethidium. In flow cytometry, ethidium can produce red fluorescence $(605 \mathrm{~nm})$ and provide an index of intracellular level of superoxide anion.

The cells were plated in $60 \mathrm{~mm}$ diameter plates at a concentration of $4 \times 10^{6}$ per plate and incubated at $37^{\circ} \mathrm{C}, 5 \%$ $\mathrm{CO}_{2}$. The cells were pretreated with 51 of $0.5 \mathrm{mg} / \mathrm{ml}$ ethanolic extract from buckwheat sprout for 3, 6, 9 and $12 \mathrm{~h}$. Then $2 \mathrm{ml}$ of $10 \mu \mathrm{M}$ DCFH-DA or DHE was added and further incubated for $30 \mathrm{~min}$. Then the plate was washed with PBS twice. The cells were collected in a $15 \mathrm{ml}$ centrifuge tube and then centrifuged at $1000 \mathrm{rpm}$ for $5 \mathrm{~min}$ to remove the supernatant. And then $0.7 \mu \mathrm{PBS}$ was used to transfer the cells to a polypropylene conical tube. ROS and superoxide anion measurements were performed using a flow cytometer (fluorescence-activated cell sorter, FACSCalibur flow cytometer, Becton Dickinson, San Jose, CA) with the CellQuest software.

\subsection{Statistical analysis}

All data were triplicate and expressed as mean \pm standard deviation. Analysis of variance was performed by ANOVA procedures. Duncan's multiple-range test was used to determine the difference of means, and $p<0.05$ was considered to be statistically significant. Student's $t$-test was used to determine the difference between two means.

\section{Results and discussion}

\subsection{Effects of TEW concentrations on the antioxidant activities of ethanolic extracts from buckwheat sprout}

Fig. 1 shows the antioxidant activities of ethanolic extracts $(1 \mathrm{mg} / \mathrm{ml})$ from buckwheat sprout grown in DIW and TEW at 100, 200, 300, 400 and $500 \mathrm{ppm}$. It was found that buckwheat sprout grown in TEW at $300 \mathrm{ppm}$ had the highest DPPH radical scavenging activity, ferrous ion chelating activity and inhibitory activity toward lipid peroxi- dation. Further increase of the concentration of TEW could result in a decline in the antioxidative activities. However, the concentration of TEW showed no significant effect on the superoxide anion scavenging activity. Therefore, we concluded that TEW at $300 \mathrm{ppm}$ yielded the highest antioxidant activity of buckwheat sprout. Thus, for the subsequent tests, we only selected $300 \mathrm{ppm}$ TEW as the experimental factor using DIW as control. The amount of ethanolic extracts from buckwheat sprouts grown at DIW and $300 \mathrm{ppm}$ TEW were not significantly different, $21.57 \pm 0.44 \%$ and $23.61 \pm 1.84 \%$, respectively.

\subsection{The trace element contents, composition and flavonoid contents of buckwheat sprout}

TEW contains more than 80 trace elements. We determined the amounts of $\mathrm{Cu}, \mathrm{Zn}, \mathrm{Se}, \mathrm{Mn}$ and Fe because they might relate to the antioxidant ability. Their contents in 300 ppm TEW and buckwheat sprout are shown in Table 1. All five trace elements were significantly different between TEW and DIW. In buckwheat sprout, the amounts of $\mathrm{Cu}$, $\mathrm{Zn}$ and $\mathrm{Fe}$ were higher in TEW group than DIW group, but the amount of Se and Mn did not differ between TEW and DIW groups. The results indicated that increase of these trace elements in buckwheat sprout was due to the supplementation of TEW. Therefore, this implied that the possible harmful trace elements presented in TEW might also be absorbed by buckwheat. So the amount of $\mathrm{Cr}$, As, $\mathrm{Cd}, \mathrm{Hg}$ and $\mathrm{Pb}$ in TEW were also determined and the data are shown in Table 2. It was found that all the tested heavy metal contents did not differ between TEW and DIW with the exception of $\mathrm{Cr}$ content. Although the $\mathrm{Cr}$ content in TEW was 2.2 fold of that in DIW, the amount $(2.67 \mu \mathrm{g} / \mathrm{g})$ was not a problem in terms of safety considerations.

Buckwheat sprout grown at 300 ppm TEW had higher crude ash then that grown in DIW, but no significant differences were found in moisture, crude protein, crude fat and crude fiber contents (Table 3). This indicated that the supplement of TEW raised the level of mineral content in buckwheat sprout and increased the crude ash content.

Three different flavonoid compounds were found in buckwheat sprout, their contents followed the order: rutin $(7.62 \mathrm{mg} / \mathrm{g})>$ quercitrin $(0.21 \mathrm{mg} / \mathrm{g})>$ quercetin $(0.16 \mathrm{mg} /$ g) in wet weight basis (Fig. 2). All the flavonoid compounds did not differ between fresh buckwheat sprouts grown in TEW and DIW. Moreover, in the ethanolic extracts, all the flavonoid contents were similar in TEW and DIW groups (data not shown).

\subsection{Antioxidant activities of ethanolic extracts from buckwheat sprout}

Antioxidant activities of the ethanolic extracts from buckwheat sprout grown in TEW (300 ppm) and DIW were determined at six concentrations, $0.31,0.63,1.25$, $2.5,5$ and $10 \mathrm{mg} / \mathrm{ml}$. There was significant difference $(p<0.01)$ in the DPPH radical scavenging activity between 
A

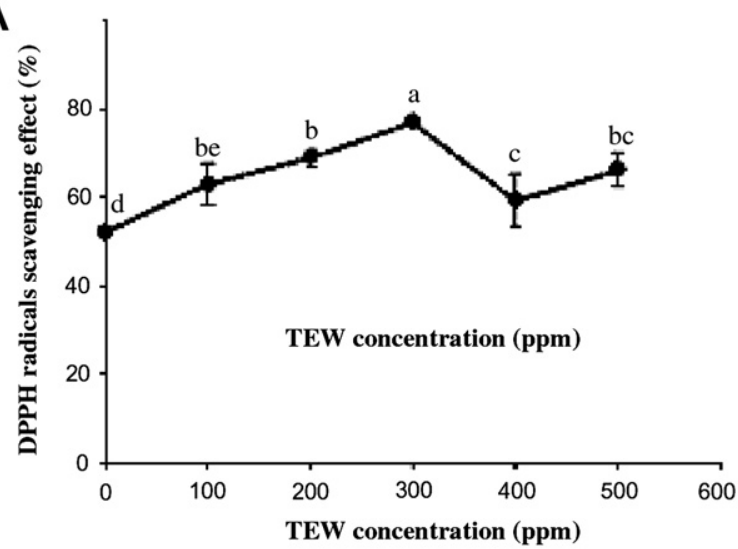

C

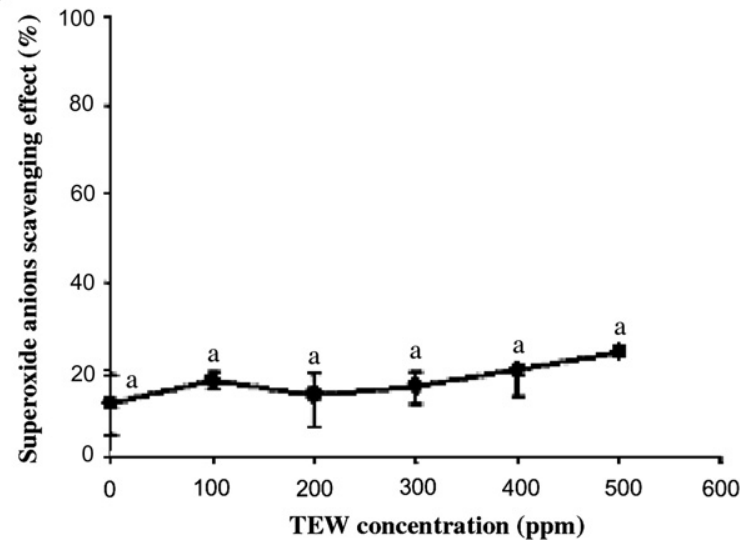

B

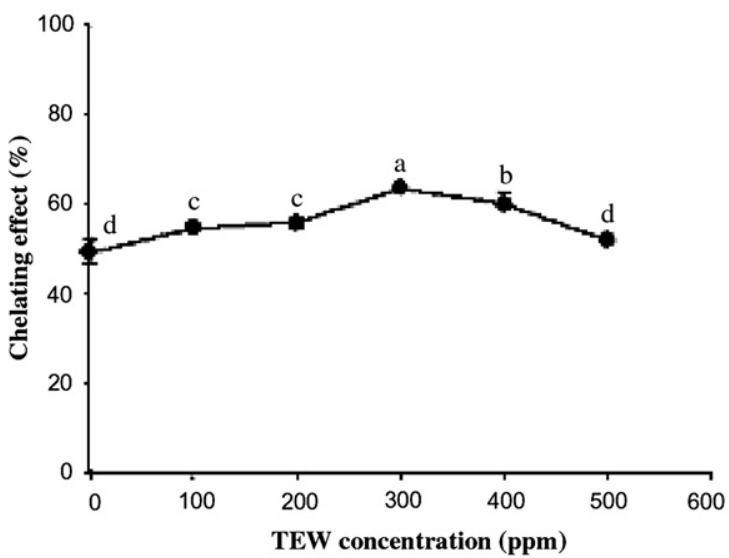

D

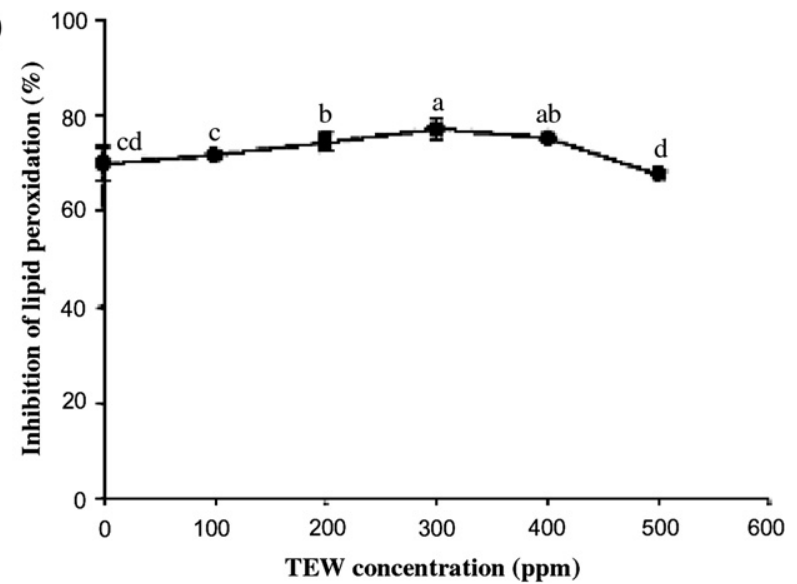

Fig. 1. Effects of the concentrations of trace element water on the antioxidative activities of the ethanolic extracts from buckwheat sprout: (A) DPPH radical scavenging activity, (B) ferrous ion chelating ability, (C) superoxide anion scavenging activity and (D) inhibition toward lipid peroxidation. $\left({ }^{\text {a }-\mathrm{d}}\right.$ The values followed by different superscripts were significantly different at significant level of 0.05 .)

Table 1

The contents of trace elements in trace element water (at $300 \mathrm{ppm}$ ), de-ionized water, and buckwheat sprout

\begin{tabular}{llllr}
\hline$\mu \mathrm{g} / \mathrm{g}$ & $\mathrm{Cu}$ & $\mathrm{Zn}$ & $\mathrm{Se}$ & $\mathrm{Mn}$ \\
\hline Water & & & & $\mathrm{Fe}$ \\
DIW & $0.30 \pm 0.003^{\mathrm{b}}$ & $8.76 \pm 0.002^{\mathrm{b}}$ & $0.13 \pm 0.04^{\mathrm{b}}$ & $0.15 \pm 0.001^{\mathrm{b}}$ \\
TEW & $2.42 \pm 0.002^{\mathrm{a}}$ & $37.24 \pm 0.004^{\mathrm{a}}$ & $0.28 \pm 0.03^{\mathrm{a}}$ & $49.77 \pm 0.02^{\mathrm{a}}$ \\
Buckwheat sprout & & & & \\
DIW group & $0.61 \pm 0.04^{\mathrm{b}}$ & $3.69 \pm 0.03^{\mathrm{b}}$ & $0.004 \pm 0.001^{\mathrm{a}}$ & $5.41 \pm 0.01^{\mathrm{a}}$ \\
TEW group & $0.74 \pm 0.01^{\mathrm{a}}$ & $4.86 \pm 0.09^{\mathrm{a}}$ & $0.007 \pm 0.002^{\mathrm{a}}$ & $5.34 \pm 0.15^{\mathrm{a}}$ \\
\hline
\end{tabular}

The contents are presented on the dry weight basis.

The values are mean \pm standard deviation $(n=3)$.

a,b Values in the same column followed by different superscripts are significantly different $(p<0.05)$.

Table 2

Heavy metal contents in buckwheat sprouts grown in trace element water (at $300 \mathrm{ppm}$ ) and de-ionized water

\begin{tabular}{llllll}
\hline Unit $(\mu \mathrm{g} / \mathrm{g})$ & $\mathrm{Cr}$ & $\mathrm{As}$ & $\mathrm{Cd}$ & $\mathrm{Hg}$ & $\mathrm{Pb}$ \\
\hline DIW group & $1.22 \pm 0.06^{\mathrm{b}}$ & $0.0022 \pm 0.0004^{\mathrm{b}}$ & $0.006 \pm 0.000^{\mathrm{a}}$ & $0.002 \pm 0.001^{\mathrm{a}}$ & $0.0164 \pm 0.0039^{\mathrm{a}}$ \\
TEW group & $2.67 \pm 0.05^{\mathrm{a}}$ & $0.0044 \pm 0.0004^{\mathrm{a}}$ & $0.006 \pm 0.000^{\mathrm{a}}$ & $0.0009 \pm 0.0004^{\mathrm{a}}$ & $0.0100 \pm 0.0007^{\mathrm{b}}$ \\
\hline
\end{tabular}

The contents are presented on the dry weight basis.

The values are mean \pm standard deviation $(n=3)$.

a,b Values in the same column followed by different superscripts are significantly different $(p<0.05)$. 
Table 3

The compositions of buckwheat sprouts grown in trace element water (at $300 \mathrm{ppm}$ ) and de-ionized water

\begin{tabular}{llllll}
\hline$\%$ & Moisture & Crude protein & Crude fat & Crude fiber & Crude ash \\
\hline DIW & $92.34 \pm 0.41^{\mathrm{a}}$ & $0.14 \pm 0.01^{\mathrm{a}}$ & $0.30 \pm 0.03^{\mathrm{a}}$ & $0.73 \pm 0.10^{\mathrm{a}}$ & $0.48 \pm 0.01^{\mathrm{b}}$ \\
TEW & $91.69 \pm 1.08^{\mathrm{a}}$ & $0.15 \pm 0.01^{\mathrm{a}}$ & $0.31 \pm 0.01^{\mathrm{a}}$ & $0.69 \pm 0.05^{\mathrm{a}}$ & $0.58 \pm 0.002^{\mathrm{a}}$ \\
\hline
\end{tabular}

The contents are presented on the wet weight basis.

The values are mean \pm standard deviation $(n=3)$.

a,b Values in the same column followed by different superscripts are significantly different $(p<0.05)$.
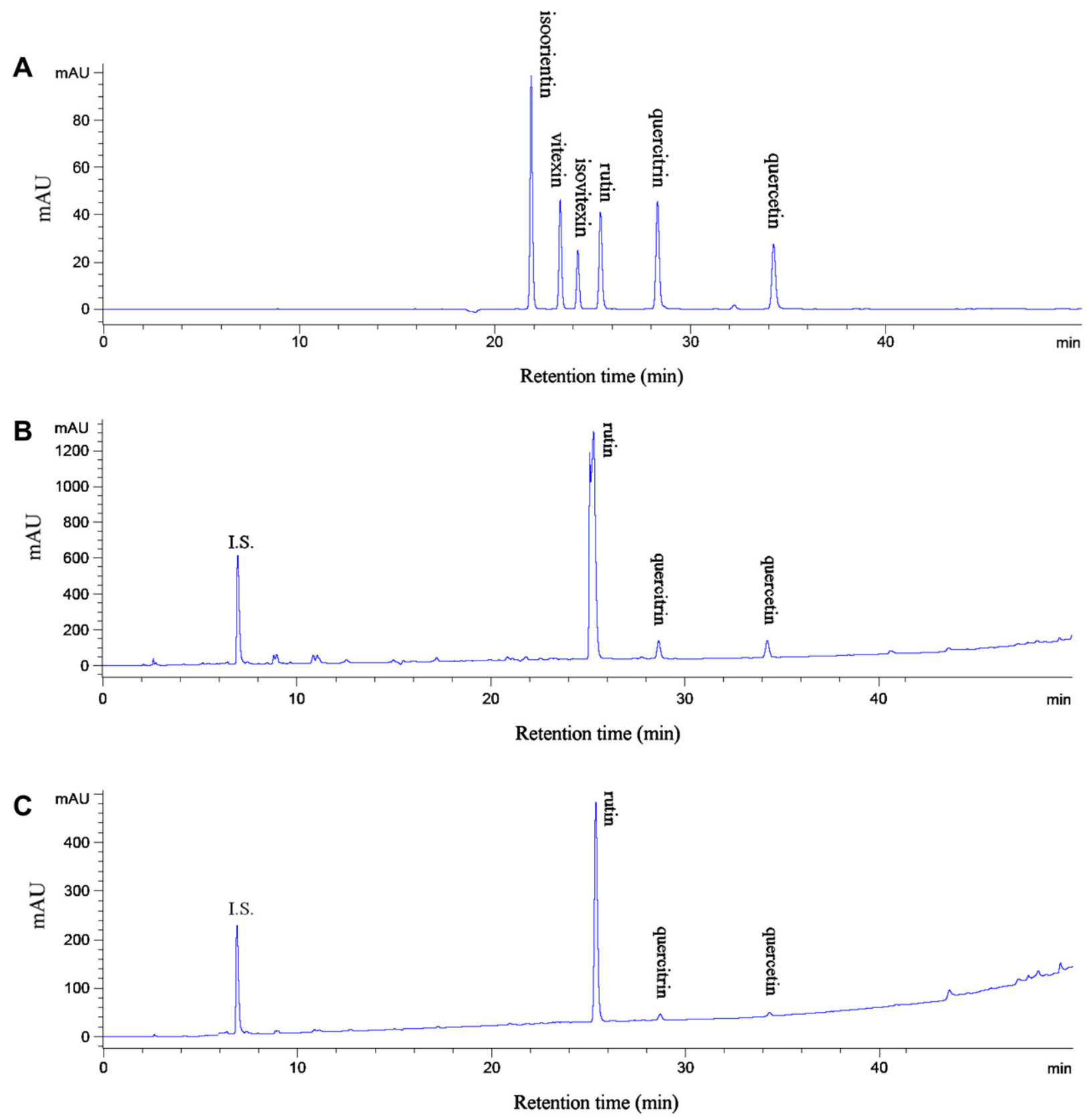

Fig. 2. Flavonoid contents in the ethanolic extract from buckwheat sprout determined by HPLC: (A) standard material, (B) DIW group and (C) TEW group.

the ethanolic extracts from buckwheat sprouts grown in TEW and DIW at the concentrations of $0.63 \mathrm{mg} / \mathrm{ml}$ or higher (Fig. 3A). When compared to ascorbic acid, $\alpha$-tocopherol and BHT, the DPPH radical scavenging activity in the extract from buckwheat sprout was lower than that of all three antioxidants. Our data also showed the extract from TEW group showed significantly higher ferrous ion chelating activity than the extract from DIW 
A

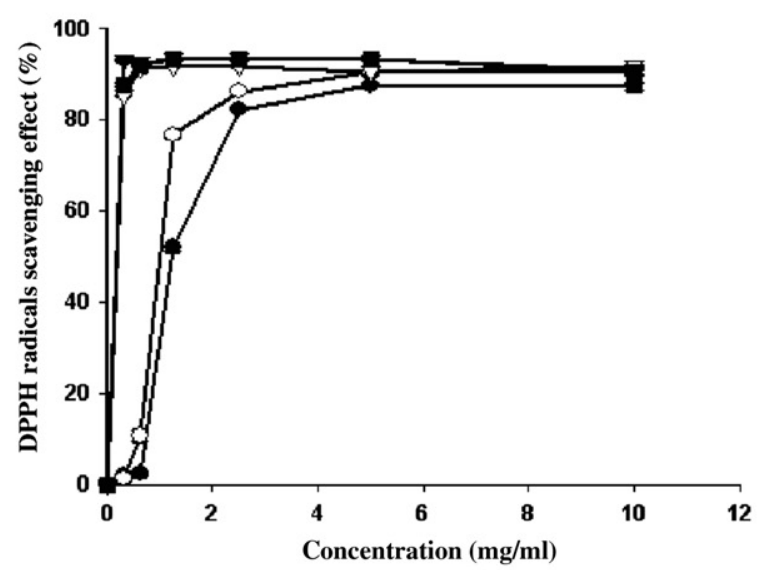

C

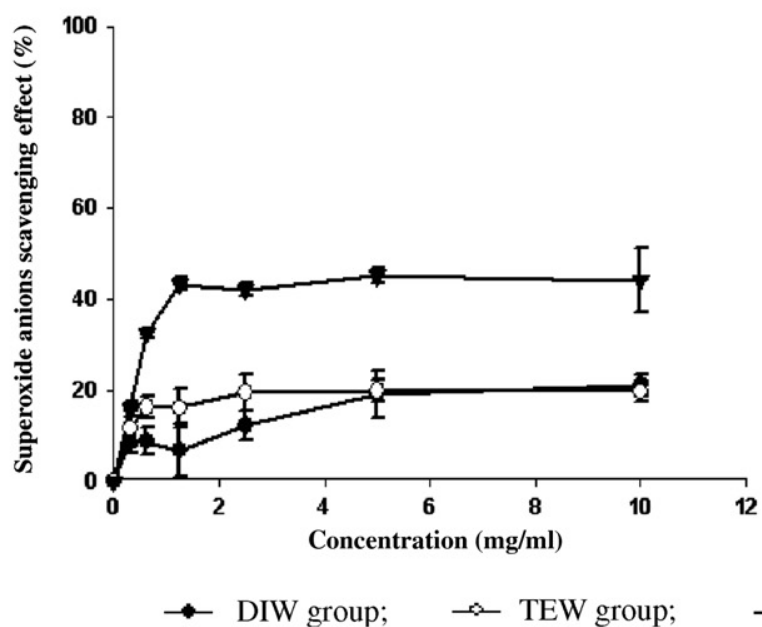

B

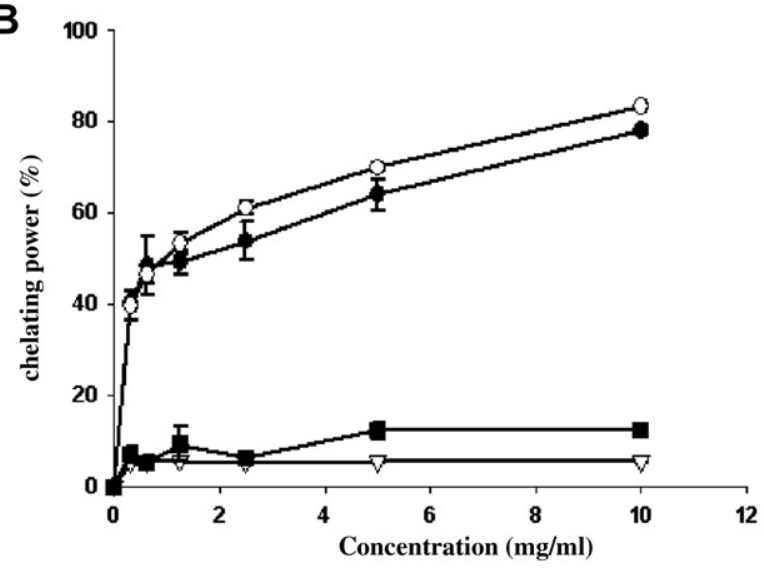

D

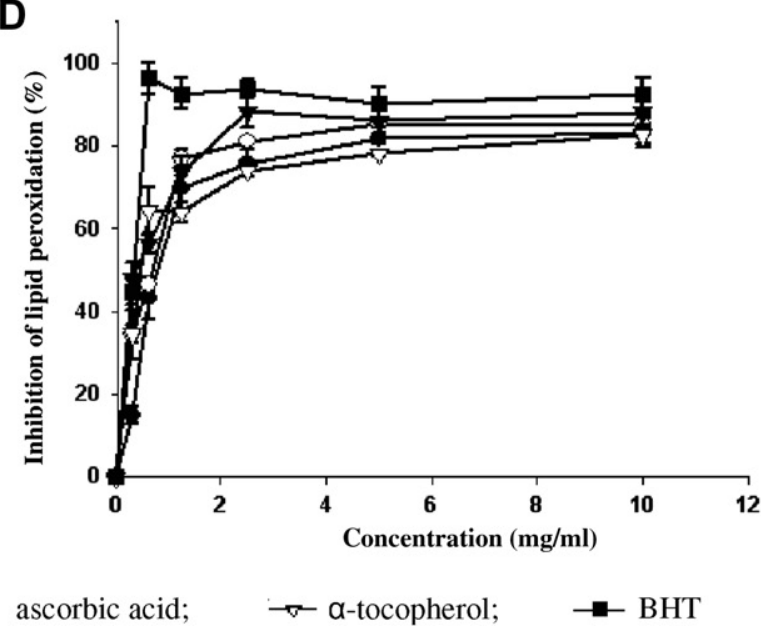

Fig. 3. Antioxidative activities of the ethanolic extract of buckwheat sprout grown in DIW and TEW: (A) DPPH radical scavenging activity, (B) ferrous ion chelating ability, (C) superoxide anion scavenging activity and (D) inhibition toward lipid peroxidation.

group ( $p<0.01$ ) at concentrations of $1.25 \mathrm{mg} / \mathrm{ml}$ or higher (Fig. 3B). Since $\alpha$-tocopherol and BHT do not have metal ion chelating functional groups, they showed poor ferrous ion cheating activity. Our data also showed that ascorbic acid did not have the ability to bond ferrous ion. It has been pointed out that metal ions from $\mathrm{FeCl}_{3}, \mathrm{CuCl}_{2}$ or $\mathrm{FeCl}_{2}$ can promote the peroxidation of ascorbic acid and decrease its ferrous ion chelating activity (Satoh \& Sakagami, 1997). Both the TEW and DIW groups showed low superoxide anion scavenging activities, but TEW groups had slightly higher scavenging activity than DIW groups (Fig. 3C). Ascorbic acid had high superoxide anion scavenging activity, but $\alpha$-tocopherol and BHT did not show inhibitory activity toward superoxide anions. In fact, Kim, Han, Moon, and Rhee (1995) even reported that $\alpha$-tocopherol and BHT promoted the production of superoxide anions. The ability to inhibit the lipid peroxidation was higher in TEW group than in DIE group $(p<0.01)$ in the concentration range of $0.31-5 \mathrm{mg} / \mathrm{ml}$. It was found that the inhibitory activity of the ethanolic extract from buckwheat sprout was similar to those of $\alpha$-tocopherol and ascorbic acid, but lower than that of BHT (Fig. 3D).
In general, our data indicated that the ethanolic extract from buckwheat sprout showed high reducing power, DPPH radical scavenging activity, ferrous ion chelating activity and inhibitory activity toward lipid peroxidation, but poor superoxide anion scavenging activity. And buckwheat sprout grown in TEW group had higher DPPH radical scavenging activity, reducing power, ferrous ion chelating activity, superoxide anion scavenging activity and inhibitory activity toward lipid peroxidation than the sprout grown in DIW group. Since the levels of rutin and other tested flavonoid compounds did not differ between buckwheat sprout grown in TEW and DIW, but the levels of tested trace elements did increase in the TEW group, the higher antioxidant activity in the TEW group might due to the trace elements in TEW.

\subsection{Cell viability}

Effects of the ethanolic extracts from buckwheat sprouts grown in TEW and DIW on the viability of human Hep G2 cell were tested at five different concentrations, $0.05,0.1$, $0.2,0.5$ and $1 \mathrm{mg} / \mathrm{ml}$. At low concentrations, 0.05 and 


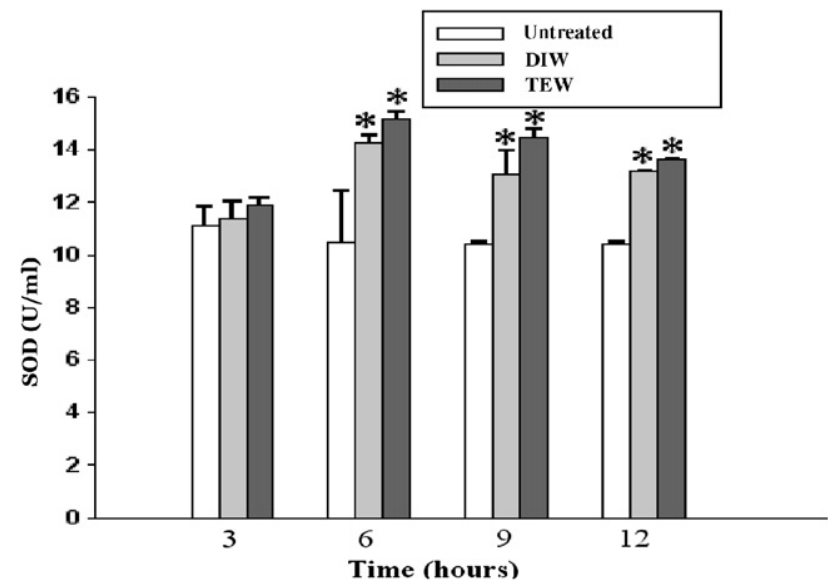

Fig. 4. Effect of the ethanolic extract from buckwheat sprout on the superoxide dismutase (SOD) activity in human Hep G2 cells. $\left(^{*}:\right.$ The value is significant difference to the untreated value at each sampling time.)

$0.1 \mathrm{mg} / \mathrm{ml}$, both the ethanolic extracts in TEW and DIW groups showed no cyto-toxicity toward human Hep G2 cells. At high concentrations, $0.5 \mathrm{mg}$ and $1 \mathrm{mg} / \mathrm{ml}$, significant toxicity was observed in both the extracts in TEW and DIW. We selected the medium concentration, $0.2 \mathrm{mg} / \mathrm{ml}$, for the subsequent tests for evaluating the antioxidant status in human Hep G2 cells because the cell viability was maintained higher than $80 \%$ up to $72 \mathrm{~h}$. It was also noted that effect of the extract from buckwheat sprout did not differ between TEW and DIW groups at all tested concentrations.

\subsection{Intracellular activities of $S O D$ and $G P x$}

Human Hep G2 cells were pretreated with $0.2 \mathrm{mg} / \mathrm{ml}$ of the ethanolic extracts in TEW and DIW groups for 3, 6, 9 and $12 \mathrm{~h}$. The effect of the extracts on the intracellular SOD activity was determined and the data are shown in Fig. 4. It was found that the pretreatment of the extracts significantly increased the SOD activity $(p<0.01)$. When pretreated with the extracts for 6,9 and $12 \mathrm{~h}$, the SOD activity was higher in TEW group than that in DIW group $(p<0.001)$. This might be because the extract in TEW group had higher trace elements $(p<0.01)$, such as $\mathrm{Cu}$ and $\mathrm{Zn}$, that could promote the SOD activity. As shown in Fig. 5, the pretreatment of the extracts also increased the GPx activity in human Hep G2 cells at 6 and $9 \mathrm{~h}$ $(p<0.01)$; however, no significant difference was found between the extracts in TEW and DIW groups. It has been shown that Se can influence GPx activity (Brigelius, 1999; Tinggi, 2003). It was suspected that the amount of Se did not differ in buckwheat sprout grown in TEW and DIW, therefore, no difference was found in the GPx activity.

\subsection{Intracellular ROS and superoxide anion}

The fluorescence intensity of DCF was used as the index to represent the amount of intracellular ROS level in human Hep G2 cells. As shown in Fig. 6, the extracts from

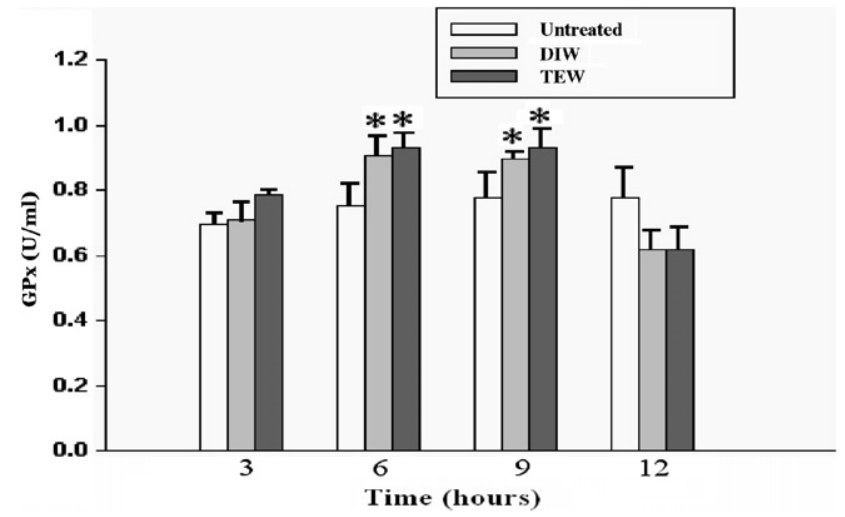

Fig. 5. Effect of the ethanolic extract from buckwheat sprout on the glutathione peroxidase (GPx) activity in human Hep G2 cells. ${ }^{*}$ : The value is significant difference to the untreated value at each sampling time.)

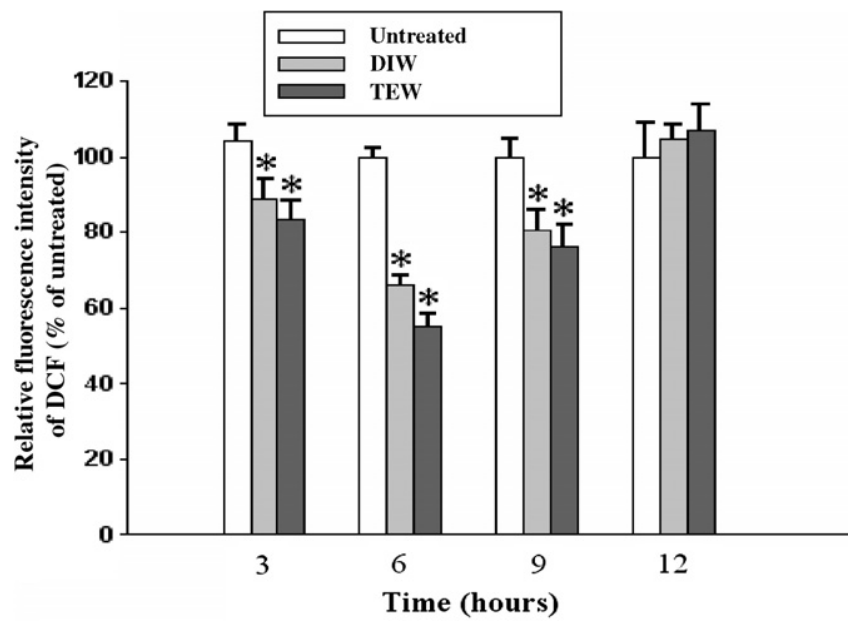

Fig. 6. Effect of the ethanolic extract from buckwheat sprout on the content of reactive oxygen species (ROS) in human Hep G2 cells. $\left({ }^{*}\right.$ : The value is significant difference to the untreated value at each sampling time.)

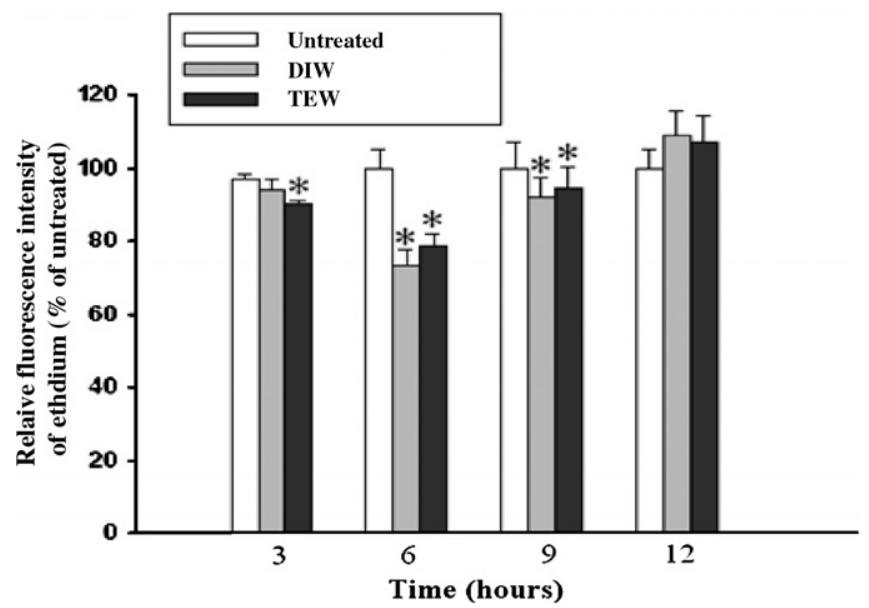

Fig. 7. Effect of the ethanolic extract from buckwheat sprout on the content of superoxide anion in human Hep G2 cells. ( ${ }^{*}$ : The value is significant difference to the untreated value at each sampling time.) 
both TEW and DIW groups reduced the production of ROS when the cells were pretreated with the extract for 3, 6 and $9 \mathrm{~h}$. Moreover, at $6 \mathrm{~h}$ the extract from TEW group resulted in significantly lower ROS level than the extract from DIW group. This finding agreed with higher SOD activities found in TEW group at $6 \mathrm{~h}$ because in TEW group SOD might convert ROS to hydrogen peroxide more effectively. Our data indicated that the supplement of TEW to buckwheat increased the activity of SOD, thus reduced the levels of ROS in human Hep G2 cells. The extracts from buckwheat also significantly decreased the level of superoxide anions in the cells (Fig. 7). However, the production of intracellular superoxide anions did not vary between TEW and DIW groups.

\section{Conclusions}

The application of trace element water to enhance the antioxidant status of buckwheat sprout appears to be promising. Although it was still not clear what the key trace elements were responsible for the increase of the antioxidant activities, we have demonstrated that the beneficial effect of trace elements on the antioxidant activity could be accomplished with the supplementation of trace element water.

\section{References}

Abeywardena, M. Y., \& Head, R. J. (2001). Dietary polyunsaturated fatty acid and antioxidant modulation of vascular dysfunction in the spontaneously hypertensive rat. Prostaglandins Leukotrienes and Essential Fatty Acids, 65, 91-97.

AOAC (1997). Official methods of analysis (16th ed.). Washington, DC: Association of Official Analytical Chemists.

Brigelius, F. R. (1999). Tissue-specific functions of individual glutathione peroxidase. Free Radical Biology and Medicine, 27, 951-965.

Dinis, T. C., Maderia, V. M., \& Almeda, L. M. (1994). Action of phenolic derivatives (acetaminophen, salicylate and 5-aminosalicylate) as inhibitors of membrane lipid peroxidation and as peroxyl radical scavengers. Archives of Biochemistry and Biophysics, 315, 161-169.

Geret, F., \& Bebianno, M. J. (2004). Does zinc produce reactive oxygen species in Ruditapes decussates? Ecotoxicology and Environmental Safety, 57, 399-409.
Kim, S. J., Han, D., Moon, K. D., \& Rhee, J. S. (1995). Measurement of superoxide dismutase-like activity of natural antioxidant. Bioscience Biotechnology and Biochemistry, 59, 822-826.

Kreft, I., Fabjan, N., \& Yasumoto, K. (2006). Rutin content in buckwheat (Fagopyrum esculentum Moench) food materials and products. Food Chemistry, 98, 508-512.

Kreft, S., Knapp, M., \& Kreft, I. (1999). Extraction of rutin from buckwheat (Fagopyrum esculentum Moench) seeds and determination by capillary electrophoresis. Journal of Agricultural and Food Chemistry, 46, 2020-2023.

LeBel, C. P., Ishiropoulos, H., \& Bondy, S. C. (1992). Evaluation of the probe $2^{\prime}, 7^{\prime}$-dichlorofluorescein as an indicator of reactive oxygen species formation and oxidative stress. Chemical Research in Toxicology, 5, 227-231.

Misuda, H., Yasumoto, K., \& Iwami, K. (1966). Antioxidative action of indole compounds during the autooxidation of linoleic acid. Eiyo to Shokuryo, 19, 210-214.

Park, C. H., Kim, Y. B., Choi, Y. S., Heo, K., Kim, S. L., \& Lee, K. C. (2000). Rutin content in food products processed from groats, leaves and flowers of buckwheat. Fagopyrum, 17, 63-66.

Prohaska, J. R., \& Luckasewycz, O. A. (1981). Copper deficiency suppresses the immune response of mice. Science.

Roback, J., \& Gryglewski, R. J. (1988). Flavonoids are scavengers of superoxide anions. Biochemical Pharmacology, 17, 837-841.

Roussel, A. M., Anderson, R. A., \& Favier, A. E. (2000). Trace elements in man and animals. New York: Kluwer Academic/Plenum Publishers.

Satoh, K., \& Sakagami, H. (1997). Effect of metal ions on radical intensity and cytotoxic activity of ascorbate. Anticancer Research, 17, $1125-1130$

Shimada, K., Fujikawa, K., Yahara, K., \& Nakamura, T. (1992). Antioxidative properties of xanthan on the autoxidation of soybean oil in cyclodextrin emulsion. Journal of Agricultural and Food Chemistry, 40, 945-948.

Steinman, H. M. (1982). Superoxide dismutase: Protein chemistry and structure-function relationships. In L. W. Oberley (Ed.), Superoxide dismutase (pp. 11-68). Boca Raton, FL: CRC Press.

Tinggi, U. (2003). Essentiality and toxicity of selemium and its status in Australia: A review. Toxicology Letters, 137, 103-110.

Wang, H., \& Joseph, J. A. (1999). Quantifying cellular oxidative stress by dichlorofluorescein assay using microplate reader. Free Radical Biology and Medicine, 27, 612-616.

Wichtel, J. J. (1998). A review of selenium deficiency in grazing ruminants. Part 1: New roles for selenium in ruminant metabolism. New Zealand Veterinary Journal, 46, 47-52.

Wojcicki, J., Barcew-Wiszniewska, B., Samochowiec, L., \& Rozewicka, L. (1995). Extractum Fagopyri reduces artheriosclerosis in high-fat diet fed rabbits. Die Pharmazie, 50, 560-562. 